\title{
Rebuilding after COVID: Planning Systems of Care for the Future
}

\author{
Warren Newton, MD, MPH, Lars Peterson, MD, PhD, Zachary J. Morgan, MS, \\ Andrew Bazemore, MD, MPH, Michael Magill, MD, John Brady, MD, and \\ Robert Phillips, MD, MSPH
}

( J Am Board Fam Med 2020;33:485-488.)

As we write this editorial, the first phase of the COVID-19 pandemic is hitting with a huge impact in New York City and many other communities. As inpatient and intensive care unit care surge, most primary care virtualizes, and elective procedures disappear, it is clear that health care is being transformed dramatically and quickly. It is also clear that the impact of COVID-19 on the organization of health care will last much longer than the pandemic - and not just telehealth. With many clinicians working without adequate protective equipment, practices facing bankruptcy in weeks, and hospitals furloughing many staff members, the psychological and financial impact will be felt for a long time.

How will we rebuild? A pressing question is what will happen to small independent practices. Such practices are especially vulnerable to the COVID19 storm $^{1}$ : in most of the country, the visit drop means a dramatic drop of income, and there is little financial reserve. Yet, it is this kind of practice that gave birth to family medicine, which gave us a commitment to substantial continuing medical education, residency training based in continuity of care, clinical flexibility, and broad scope of care, including behavioral health and celebration of service to communities - the very features so valuable in the response of family physicians to the pandemic.

Small independent practices still have much to contribute. For the challenges we face, even before COVID-19, small independent practices' nimbleness,

Submitted 9 April 2020.

From: American Board of Family Medicine, Lexington, $\mathrm{KY}$ (WN, LP, ZJM, AB, MM, JB, RP).

Conflict of interest: The authors are employees of the ABFM.

Corresponding author: Warren P. Newton, MD, MPH, American Board of Family Medicine, 1648 McGrathiana Pkwy, Ste 550, Lexington, KY 40511-1247 (E-mail: wnewton@ theabfm.org). patient-centeredness, capacity for innovation, and lower cost of care have an impressive track record. ${ }^{2-5}$ The reorganization package must be multifaceted but will include capital to support redesign, practice networking and care facilitation, integration with small hospitals and public health, and an improved health workforce pipeline with more widely distributed residencies and other health professional training. The Vermont Blueprint for Health, under a Medicare waiver, showed that small, independent practices can be supported with community-based resources to transform, improve quality, and lower costs. ${ }^{4}$ New Mexico's long-running Health Education Rural Outreach programs and cooperative extension-like model for health care has similarly demonstrated important practice, public health, and workforce outcomes. ${ }^{6,7}$ The American Board of Family Medicine (ABFM) will work with all partners to move this agenda forward, championing innovations driven in and by small practices, targeting policy research, and providing direct support of quality improvement, more meaningful measurement, and appropriate reimbursement through its PRIME Registry. ${ }^{8}$

ABFM believes, however, that it is also important for our specialty to begin to engage large health systems. The reality is that most family physicians in 2020 are employed. If Marcus Welby returned to TV land, he would work for Kaiser Permanente! ABFM continuing certification data show that two-thirds of certified family physicians are employed, about half of these by health systems, and only $16 \%$ remain in independent practice. Although variation exists in the proportion of employed physicians across states, as Figure 1 demonstrates, it is important for our specialty to recognize and respond to this trend. By 2018, the majority of physicians in the United States were employed, ${ }^{10}$ and family physicians are leaders in 
this trend, which is a result of hospital consolidation, capital demands for electronic health records and liability, and the promise of payment for population health.

Employment by ever-larger health systems can bring significant challenges, as ABFM research has documented. Over the last decade, we have seen a substantial narrowing of the scope of practice; graduating residents often cannot find jobs with the scope of practice they are trained for and intend to provide. ${ }^{11,12}$ Coordination of care has become more difficult. ${ }^{13}$ Our professionalism is at risk as our environment is increasingly shaped to make it harder for us to connect with patients whenever and wherever they need us and to provide the care they need while on "eat what you treat" reimbursement model. ${ }^{14}$ All these trends have been accelerated in some large health systems, and they occur in an era of the beginning of the decline in life expectancy in the United States over the past 5 years ${ }^{15}$ and worsening overall population health outcomes compared with similar countries. ${ }^{16}$

A robust family medicine and primary care presence within large systems of care can bring important potential benefits. Huge capital infusions are needed for primary care-and much more will be needed as we reorganize primary care after the current global pandemic. Large group practices and health systems may offer resources unavailable to many small independent practices, such as teleconsults and specialized behavioral health, organized pharmacy, targeted care management, data analytics, quality dashboards, and information technology and other technical support. Where leadership can harness the power of family medicine and primary care, health systems are implementing creative approaches to address population health and address disparities in the health of communities.

A basic question is what is the right organization of a network of primary care practices? As large health systems expand their footprint, they face the challenge of effectively coordinating the efforts of the scores or hundreds of practices that form the foundation of their service area. Some build around regional centers with substantial infrastructure-a "destination center" with some combination of family medicine, internal medicine, ob/gyn, pediatrics, and urgent care. Others emphasize a network of smaller practices-with family physicians and other clinicians-providing care to a broad array of patients within communities with effective connections to health system resources. Of course, there is a continuum and much depends on the populations served and how the health care system resolves the dynamic tension between central and distributed services.

A closely related issue is the role of primary care in improving the health of populations. In the wake of a National Academies call for more alignment between primary care and public health ${ }^{17}$ and the birth of Accountable Care Organizations, the prospect of payment for population health has spawned many ideas and even more consultants. Traditional public health approaches emphasize direct engagement with the population-around smoking, physical activity, and other primary risk factors. In contrast, networked primary care offices, backed up by targeted analytics and coupled with the power of family physicians engaging individual patients, have the potential to drive major improvements in health and reductions in aggregate population risk. Yet, another strategy is represented by "disruptive" approaches often funded by venture capital, which offer new, less expensive platforms for targeting very specific populations. What is the right role for primary care in improving population health—and how do we decide?

The workforce required for robust primary care and improved population health is a third issue in need of further evidence and dialog. The last decade has seen an explosion of new and expanding allopathic and osteopathic medical schools, nurse practitioner and doctorate of nursing practice training programs, and physician assistant training programs, all growing to the limit of their students' debt. We should recognize that new technologies and professions commonly migrate "up-market"18 against resistance from incumbents. Yet, addressing the quadruple aim requires team-based interprofessional care. In this environment, the roles of family physicians will be essential, although different from the Marcus Welby stereotype. Fortunately, one characteristic of family physicians is that they readily adapt to meet evolving needs of patients and health systems.

Exactly how primary care teams will be constructed and work together, however, is often overlooked. What is the right mix and organization of clinicians to include the medical office assistants as well as clinical pharmacists, care managers, patient educators, integrated behavioral health providers, community health workers, and traditional public 
health? How do we distribute specific tasks among interprofessional team members while ensuring flexible and coherent care in support of patient values and goals? How will we engage patients, not only in shared decision making but also in every aspect of our practices, from patient education to quality improvement to governance? And, most fundamentally, how will we empanel family physicians and the team? Empanelment is foundational to population health, coordination of care, and equity-and often incompletely understood by clinicians, health systems, and payers and hugely at risk with free market telemedicine.

Finally, how do we support family physicians to become health system leaders? Here, again, the solution is likely to be multifaceted. Medical school and residency education provide foundational skills, including additional degree programs. Broad scope clinical experience, with the opportunity to work with many other specialties and professions, will be critical, as will career ladders that give family physicians the experience of leading progressively larger system initiatives. Experiences provided by many American Family Physician state chapters and medical societies provide an important breadth of perspective. Beyond these, however, there is a need for targeted midcareer and senior physician leadership development. Nursing has been very successful in developing a pipeline for nurse hospital CEOs, and Executive Leadership in Academic Medicine ${ }^{19}$ has an outstanding track record in developing women leaders in academic medicine. ABFM believes that our specialty must develop a new kind of leadership training. We are committed to doing our share, directly through our Pisacano and Puffer fellowships and policy research experiences, but we will also support new models for developing health system and university leaders, scaled to the size of the need. In this light, we are excited by what the Association of Departments of Family Medicine has begun to do with its Leadership Education for Academic Development and Success (LEADS) fellowship. $^{20}$

COVID-19 will bring change long after the pandemic is over. In this context, ABFM believes that there is an opportunity for our specialty to be proactive-to preserve and enhance what independent practices bring to communities, while engaging with large health systems as partners. We look for partners in innovation and lasting transformation.
To see this article online, please go to: http://jabfm.org/content/ 33/3/485. full.

\section{References}

1. Health Landscape. Coronavirus Pandemic-Related Potential Family Medicine Office Closures and Economic Impact, April through June 2020. Washington, DC: Health Landscape; 2020.

2. Casalino LP, Pesko MF, Ryan AM, et al. Small primary care physician practices have low rates of preventable hospital admissions. Health Aff (Project Hope) 2014;33:1680-8.

3. Glancey KK, Kennedy JG. Achieving PCMH status may not be meaningful for small practices. Ann Fam Med 2016;14:4-5.

4. Mostashari F. The paradox of size: how small, independent practices can thrive in value-based care. Ann Fam Med 2016;14:5-7.

5. Liaw WR, Jetty A, Petterson SM, Peterson LE, Bazemore AW. Solo and small practices: a vital, diverse part of primary care. Ann Fam Med 2016;14:8-15.

6. Kaufman A, Roth PB, Larson RS, et al. Vision 2020 measures University of New Mexico's success by health of its state. Am J Prev Med 2015;48:108-15.

7. Phillips RL, Jr., Kaufman A, Mold JW, et al. The primary care extension program: a catalyst for change. Ann Fam Med 2013;11:173-8.

8. Phillips RL. The PRIME registry helps thousands of primary care clinicians liberate EHR data and prepare for MIPS. J Am Board Fam Med 2017;30:559.

9. Peterson LE, Morgan Z. ABFM family medicine certification examination registration data, 2017 to 2019 Accessed 3/2/20.

10. JAMA Career Center. Employment trends report. Available from: https://careers.jamanetwork.com/article/ employment-trends-report-practice-arrangements/. Acccessed April 9, 2020.

11. Barreto TW, Eden AR, Hansen ER, Peterson LE. Barriers faced by family medicine graduates interested in performing obstetric deliveries. J Am Board Fam Med 2018;31:332-333.

12. Eden AR, Barreto T, Hansen ER. Experiences of new family physicians finding jobs with obstetrical care in the USA. Fam Med Com Health 2019;7: $\mathrm{e} 000063$.

13. Reilly BM. Waste, worry, and the seven sins of medicine. N Engl J Med 2020;382:1295-1297.

14. Phillips RL, Bazemore AW, Newton WP, Byyny RL. Medical professionalism: a contract with society. Pharos 2019;2-7.

15. Woolf SH, Schoomaker H. Life expectancy and mortality rates in the United States, 1959-2017. JAMA 2019;322:1996-2016. 
16. National Research Council, Institute of Medicine. U.S. Health in International Perspective: Shorter Lives, Poorer Health. Washington, DC: National Academies Press; 2013.

17. Committee on Integrating Primary Care and Public Health, Board on Population Health and Public Health Practice, Institute of Medicine. Primary Care and Public Health: Exploring Integration to Improve Population Health. Washington, DC: National Academies Press; 2012.
18. Christensen CM. The Innovator's Dilemma: When New Technologies Cause Great Firms to Fail. Boston, MA: Harvard Business School Press; 1997.

19. Richman RC, Magrane D. Spotlight on the executive leadership in academic medicine program for women. Association of American Medical Colleges. Accessed April 9, 2020.

20. ADFM LEADS: leadership education for academic development and success. Available from: https:// www.adfm.org/programs/leads-fellowship/. Accessed April 9, 2020. 